patients was almost certainly due to twiddler's syndrome ${ }^{2}$ - that is, manipulation by the patient.

Cassey et al and Ball et al reported the use of a metal port in similar patients to ours and found a high incidence of problems including venous thrombosis, occlusion of the catheter, and detachment or fracture of the catheter. ${ }^{3+}$ Cassey et al suggested that these ports should be used only in inpatients because of septic complications. Our only case of reversible occlusion of the catheter occurred while the patient was in hospital. Thrombosis of the catheters was avoided by flushing them after use and regular monthly flushing with heparinised saline $(10 \mathrm{U} / \mathrm{ml})$ when they were not in use. No cases of sepsis occurred despite self treatment at home. We attribute this to careful selection of the patients and training and to the nature of the infused fluid (antibiotics rather than nutrition or chemotherapy). A comparative study of different devices is required.

The plastic implantable port is cheaper than alter- native metal ports but more expensive than external silicone catheters, this being offset by the reduction in aftercare necessary and the lack of septic complications. We therefore recommend the use of the plastic implantable port in patients requiring intermittent but long term treatment with parenteral antibiotics. It is simple to insert and use, has a low rate of complications, is relatively cheap, and is cosmetically preferable to the patient.

1 Thompson AM, Kidd E, McKenzie M, Parker AC, Nixon SJ. Long term central venous access: the patient's view. Intensive Therapy and Clinical Monitoring 1989;May:142-5.

2 Gebarski SS, Gebarski AS. Chemotherapy port "twiddler's syndrome." Cancer $1984 ; 54: 38-9$.

3 Cassey J, Ford WDA, O'Brien L, Martin AJ. Totally implantable system for venous access in children with cystic fibrosis. Clin Pediatr (Phila) venous access

4 Ball ABS, Duncan FR, Foster FJ, Davidson TI, Watkins RM, Hodson ME Long term venous access using a totally implantable drug delivery system in patients with cystic fibrosis and bronchiectasis. Respiratory Medicine 1989;83. $429-31$

(Accepted 19 December 1990)

\title{
Unequal pupil size in patients with unilateral red eye
}

\author{
Geoffrey E Rose, Russell V Pearson
}

\section{Moorfields Eye Hospital, London ECIV 2PD \\ Geoffrey E Rose, FRCS, senior registrar \\ Russell V Pearson, FRCS, registrar}

Correspondence to: Mr Rose.

BMF 1991;302:571-2
In general practice a red eye presents diagnostic difficulty. Identification of eyes requiring ophthalmic supervision may be based on several symptoms and signs, such as the rate of onset, presence of pain and ocular discharge, corneal clarity, and visual loss. Pupillary constriction (miosis) is an accepted accompaniment of intraocular inflammation and also forms part of the ocular response to injury. Using methods readily available in general practice, we measured the incidence of clinically detectable anisocoria (unequal pupillary size) in patients with unilateral red eye.

\section{Patients, methods, and results}

Patients consecutively presenting to the accident and emergency department of this hospital with unilateral red eye had one of eight main diagnoses (table). A single observer assessed pupil diameters (to the nearest $0.5 \mathrm{~mm}$ during distance fixation) on a half pupil scale. Room illumination was of moderate intensity (about 1000 lux). An ophthalmic history was taken and examination performed.

Continuous variables were compared by analysis of variance and two tailed unpaired Student $t$ tests. Absolute frequencies were compared by the $\chi^{2}$ statistic and deviations from random probability (proportion) assessed with the binomial theory approximated to the standardised normal deviate. ${ }^{2}$

The average age in the eight diagnostic groups was different $(\mathrm{F}=4.92 ; \mathrm{p}<0.001)$ and the sex distribution varied somewhat. The table shows the number of patients with and the degree of anisocoria. When only the patients with anisocoria were considered the proportion with miosis on the affected side (red eye smaller anisocoria) was significantly different from random for marginal keratitis $(9 / 10$ patients, $p<0.03)$, acute anterior uveitis $(22 / 24$ patients, $\mathrm{p}<0.0002)$, and corneal abrasion $(20 / 21$ patients, $p<0.0001)$. In $7 \%$ of patients with mild eye conditions the pupil of the red eye was smaller by $0.5 \mathrm{~mm}$ or more compared with $39 \%$ of patients with serious eye diseases $\left(\chi^{2}=49 \cdot 2\right.$, $\mathrm{p}<<0 \cdot 0001)$. The proportions were also significantly different when the red eye pupil was smaller by $1 \mathrm{~mm}$ or more (table; $\chi^{2}=22 \cdot 0, \mathrm{p}<0 \cdot 0001$ )

\section{Comment}

A population sample drawn from an ophthalmic accident and emergency department might be biased towards more severe, more protracted, or partially treated eye diseases. Similarly, variability in measurement and the use of a single skilled observer could bias the results-albeit in a fashion likely to reduce the chances of incorrect conclusion. In this study neither the reproducibility of measurement nor the applicability to general practice has been examined.

Variations in age and sex distribution between the diagnostic groups were comparatively small. Though adult pupil size decreases with age $^{3}$ and the mean ages differ between the eight groups (table), these factors should not influence deductions based on our results as we compared affected pupils with their fellows-that is, we measured anisocoria. Similarly, the fact that clinically detectable physiological anisocoria may

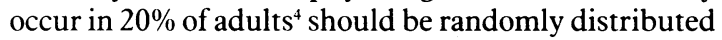
in our sample and should not therefore invalidate our conclusions.

In nearly $40 \%$ of patients with serious eye diseases but only $7 \%$ with mild diseases the red eye was smaller

Clinical details of patients presenting with unilateral red eye

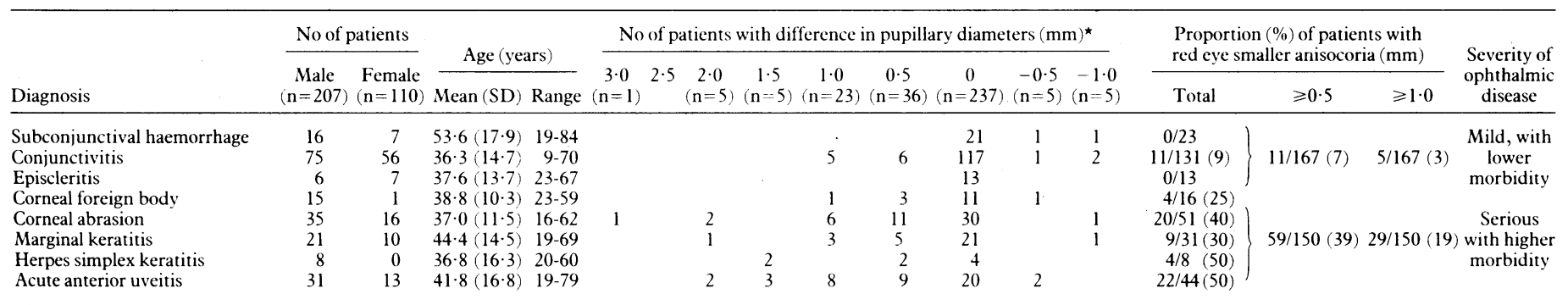

$\star$ Unaffected-red eye. 
by $0.5 \mathrm{~mm}$ or more, these proportions being significantly different $(p<0.0001)$. Visual estimation of pupil size is accurate to about $0.2 \mathrm{~mm}^{5}$ so detecting anisocoria of $0.5 \mathrm{~mm}$ or more presents no clinical difficulty.

For practical purposes, therefore, miosis in the affected eye of a patient with unilateral red eye may indicate serious eye disease. We found that when an inflamed eye shows $0.5 \mathrm{~mm}$ or more miosis relative to the unaffected eye the probability of serious eye disease is nine times greater than that of mild disease (relative risk, with $95 \%$ confidence interval 5 to 18 , logit method). Though relative miosis is more common in serious eye disease, a dilated pupil does not necessarily indicate an innocuous condition-for example, acute angle closure glaucoma may present as an inflamed eye with a dilated pupil.

1 Elkington AR, Khaw P'T. The red eye. BMf 1988;296:1720-4.

2 Armitage P. Statistical methods in medical research. Oxford: Blackwell Scientific, 1985:111-5.

3 Loewenfeld IE. Pupillary changes related to age. In: Thomsen HS, Daroff R, Frisen L, eds. Topics in neuro-ophthalmology. Baltimore: Williams and Wilkins, 1979:124-50.

4 Meyer $\mathrm{BC}$. Incidence of anisocoria and difference in size of palpebral fissures in 500 normal subjects. Archives of Neurologv and Psychiatry 1947;57:464-8. 5 Alexandridis E. The pupil. New York: Springer Verlag, 1985.

(Accepted 12 December 1990)

\section{Medical or surgical orchidectomy: the patients' choice}

\section{J Chadwick, D A Gillatt, J C Gingell}

\section{Department of Urology, Southmead Hospital, Bristol BS10 5NB \\ D J Chadwick, FRCs, research fellow \\ D A Gillatt, FRCS, senior registrar}

J C Gingell, FRCS, consultant

Correspondence to:

Mr Chadwick.

BMf 1991;302:572
The introduction of analogues of gonadotrophin hormone releasing hormone has given patients with advanced prostatic cancer and their doctors a further method of androgen deprivation. Recent multicentre, randomised trials comparing goserelin, an analogue of luteinising hormone releasing hormone, with orchidectomy have shown that the effects of the two treatments are similar. ${ }^{1}$ There is little evidence to indicate which of the two treatments is more acceptable to patients, although studies from Austria and the United States indicate that most patients prefer medical castration..$^{23}$ A similar study has not been performed in the United Kingdom.

\section{Patients, methods, and results}

Fifty one consecutive patients with advanced prostatic cancer requiring hormone treatment were interviewed by one of us (DJC). They were told that they had cancer of the prostate; that two methods of treatment were available which by depriving the body of male hormones would probably control the tumour, one method entailing an operation to remove the testicles and the other a series of monthly injections which would be given in the hospital outpatient department or in the general practitioner's surgery; and that the treatments were equally effective and had the same side effects (hot flushes and impotence). After this explanation any questions were answered and the patient was asked which of the two methods of hormone treatment he wished to receive. A further appointment was made if the patient wanted time to consider the options or to discuss the matter with relatives.

One patient was too confused to understand his condition fully and decide on treatment. Of the remaining 50 patients, 23 chose to undergo orchidectomy and 27 to receive goserelin. The mean ages of the two groups were similar, as were the proportions of each group who had metastatic disease and whose disease had been under review before hormone treatment was started (table). There was, however, a significant difference in the ratio of inpatients to outpatients in each group $\left(\chi^{2}=9 \cdot 46, p<0 \cdot 01\right)$ : most of the patients who chose orchidectomy were inpatients at
Details of patients according to whether they requested orchidectomy or goserelin

\begin{tabular}{lcc}
\hline & $\begin{array}{c}\text { Orchidectomy } \\
(\mathbf{n}=23)\end{array}$ & $\begin{array}{c}\text { Goserelin } \\
(\mathbf{n}=27)\end{array}$ \\
\hline Mean (range) age (years) & $73 \cdot 3(57-82)$ & $74 \cdot 6(63-88)$ \\
Type of disease: & 21 & 22 \\
$\quad$ Metastatic & 2 & 5 \\
$\quad$ Advanced localised & 3 & 4 \\
Hormone treatment deferred & & 5 \\
State at time of interview: & 14 & 22 \\
$\quad$ Inpatients & 9 &
\end{tabular}

the time of their interview, whereas most of those who chose goserelin were outpatients.

\section{Comment}

It is interesting that 23 of the 50 patients chose orchidectomy. These patients preferred to have a short stay in hospital rather than commit themselves to a series of monthly visits. The convenience of the procedure, with minimal disruption of their daily life, was an important factor. The 27 patients who preferred medical treatment stated that avoidance of an operation was foremost in their minds. The fear of castration itself was mentioned by surprisingly few patients. Another reason for choosing goserelin was that treatment might be delayed if they chose orchidectomy because patients were put on the hospital waiting list. The efficacy of the treatment was of concern to all patients. Many found it difficult to believe that the two treatments were equally effective. Typically, patients would ask the doctor, "You know best. What would you choose?"

Though the patient's preference is important, other factors influence the doctor in choosing between these two treatments. These include the relative $\operatorname{costs}^{45}$ and the time required in the outpatient clinic to see patients for their monthly injections.

In conclusion, when equally effective treatments are available patients should be fully informed and their preference should be taken into account so that the treatment suits their requirements.

1 Peeling WB. Phase III studies to compare goserelin (Zoladex) with orchidecPeeling WB. Phase III studies to compare goserelin (Zoladex) with orchidectomy and with diethyls

2 Cassileth BR, Soloway MS, Vogelzang NJ, et al. Patients' choice of treatment in stage D prostate cancer. Urology 1989;33(suppl):57-62.

3 Lunglmayr G, Girsch E. In: Chisholm GD, ed. "Zoladez": a new treatment for prostate cancer. London: Royal Society of Medicine, 1987:47-51. (International Congress and Symposium Series No 125.

$4 \mathrm{McClinton} \mathrm{S}$, Moffat EF, Ludbrook A. The cost of bilateral orchidectomy as a treatment for prostatic carcinoma. Br f Urol 1989;63:309-12.

5 Neoplastic disorders. MIMS 1990;December:248.

(Accepted 8 fanuary 1991) 